ORIGINAL ARTICLE

\title{
"Of the edgelands": broadening the scope of qualitative methodology
}

\section{F Rapport, P Wainwright, G Elwyn}

J Med Ethics; Medical Humanities 2005;31:37-42. doi: 10.1136/jmh.2004.000190

In an editorial in a previous issue of this journal Rapport et al introduced the metaphor of the edgelands, arguing that the area between urban and rural landscapes serves to illustrate some of the difficulties of interdisciplinarity experienced by those who work in the medical humanities. In this paper the authors explore some specific issues of qualitative research methodology in health care research. The paper describes a broadening out of the scope of qualitative inquiry in social scientific research in health and social care. The paper explains why some new methodologies have emerged and how both old and new methodologies are grouped around three interlocking strands: narrative based, arts based, and redefined, methodology. In order to illustrate developments in this field, the authors present three examples of the use of these methodologies in practice: photo elicitation technique; discourse analytic, and interpretive anthropological, method. Finally the authors illustrate how these methodologies can give added value to health services research.

See end of article for authors' affiliations .....................

Correspondence to: Dr Frances Rapport, Julian Tudor Hart Senior Research Fellow, Primary Care Group, Swansea Clinical School, Centre for Health Improvement and Evaluation (CHIRAL), University of Wales Swansea, Singleton Park, Swansea, SA2 8PP, UK;

f.l.rapport@swan.ac.uk

Accepted for publication 22 December 2004 $\mathrm{n}$ a chapter about the changing landscape in Britain Marion Shoard writes:

We are, of course, also well aware of the great conurbations. But not of the edgelands. ${ }^{1}$

She continues:

Between urban and rural stands a kind of landscape quite different from either. Often vast in area, though hardly noticed, it is characterised by rubbish tips and warehouses, superstores and derelict industrial plant, office parks and gypsy encampments, golf courses, allotments and fragmented, frequently scruffy, farmland...This peculiar landscape is only the latest version of an interfacial rim that has always separated settlements from the countryside to a greater or lesser extent. In our own age, however, this zone has expanded vastly in area, complexity and singularity...for most of us, most of the time, this mysterious no man's land passes unnoticed: in our imaginations, as opposed to our actual lives, it barely exists...
... jungles of marshalling yards and gasometers, gravel pits, water-works and car scrapyards seem no more than repositories for functions we prefer not to think about... This is a vaguely menacing frontier land hinting that here the normal rules governing human behaviour cannot be altogether relied upon... But if we fail to attend to the activity of the interface we forfeit the chance not only to shape that change but also to influence the effects of it on other parts of the environment...'

\section{INTRODUCTION}

In the chapter quoted above Shoard describes what happens between the boundaries of town and country, between rural and urban landscapes. Shoard observes that the two do not often sit conveniently side by side, with clean dividing lines. Rather, there is between them a different kind of landscape, a transitional area that she terms the edgelands. Our preferred image of the British landscape is one of neatness, of towns demarcated from downs, of "Edinburgh Castle and the heather clad hills" (Shoard, ${ }^{1}$ p 117), but we do not notice the edgelands. These areas appear to be unplanned, uncelebrated, and often incomprehensible to those less familiar with them. This is also, however, a transitional area where most environmental change takes place.

The landscapes we tend to admire are often diverse but calm, with elements arranged in an orderly manner: slow moving streams, wide expanses of meadow, fine trees, hedgerows and small fields, typifying the English rural idyll. The edgelands, however, is the antithesis of all this, raw and rough, sombre and menacing, flaunting participation in activities we do not wholly understand. For example:

Our gardens, whether in city or village, are expected to be extravagantly manicured. Allotments, the interface's bastard half child of agriculture and horticulture, put on no such show. Laboured over at least as diligently as gardens, they none the less flaunt "unsightly" infrastructure that would be unthinkable in a garden: old piping used as plant supports, soggy carpets keeping down weeds and tool sheds built imaginatively but untidily out of packing materials. ${ }^{1}$

This description may seem an unpromising start for a paper about methodology in health 
care research. As we have argued elsewhere, ${ }^{2}$ however, the metaphor of the edgelands has resonances for the medical humanities and for the conduct of research in particular. Just as we prefer our landscape neatly arranged and pleasing to the eye, so we prefer the academic landscape laid out in conveniently demarcated areas. Disciplines have their boundaries and crossover between them is problematic. We have our own paradigms and methods, and attempts to introduce interdisciplinary collaboration across paradigms cause discomfort. Funding for such work can be difficult to obtain and the work, once finished, difficult to publish. Where inter or cross disciplinary work does develop, there is always the likelihood that either one discipline will dominate and that the new venture will be absorbed, or that a new discipline will emerge. ${ }^{3}$

Nowhere does this seem more the case than in matters of epistemology and methodology in health care research. In spite of claims that the natural sciences are no longer "the benchmark against which all cognitive endeavours must be measured" and that they have "lost this privileged position", ${ }^{4}$ a review of evidence based medicine in Europe and North America might suggest that bioscience still very much sets the benchmark. Fay may write that "philosophically the demise of science as the paradigm of intellectual activity is tied to the death of positivism and the concurrent emergence of perspectivism" (Fay, ${ }^{4}$ p 2) but this is not the view of the world as seen from the pages of the Lancet or guidelines published by the National Institute for Clinical Excellence. UK medical journals do publish reports of qualitative research, but it tends to be of a type that tries to gain respectability by aping "the reputed certainty" of the methods of the natural sciences. ${ }^{5}$ Such types of qualitative research may once have been seen as the "bastard half child" of science, shunned by more respectable members of the family, a typical dweller of the edgelands. However, just as urban sprawl tends gradually to civilise and gentrify the disreputable neighbourhoods, so some forms of qualitative research have entered the polite society of medical science. ${ }^{6}$ Allmark-for example, suggests that such research would qualify as science as defined by Karl Popper. ${ }^{6}$ In his view, qualitative studies may be part of the process of hypothesis generation, leading to later attempts at falsification like any other scientific conjecture, or they may fall completely within scientific method, offering their own conjectures and their own methods of falsification.

As with the changing landscape, however, so the edgelands moves to a new interface within qualitative methodology, between established and new methods. This interface provides a space in which new approaches can develop. It represents a territory in which new theories can be approached and new ways of asking and answering questions can be found. ${ }^{7}$ Work in this research edgelands declares itself outside the usual boundaries of qualitative methodology, and in medical journals at least, may be seen as vaguely menacing or disreputable. It tries to move on from "old school" social scientific research, to look for more freedom of expressionto find more expansive territories in which to experiment and explore theoretical underpinnings to research.

\section{MOVING AWAY FROM THE CONVENTIONAL IN QUALITATIVE INQUIRY}

There are a number of reasons why an edgelands within qualitative inquiry has begun to emerge. The way qualitative research has been conducted and findings portrayed has caused unease among some qualitative methodologists. There have been criticisms of researchers who claim a grounding in qualitative methodology but appear not to understand its theories, leading to inappropriate research design and a lack of rigour. ${ }^{810}{ }^{11}$ Many researchers appear not to recognise the difference between methodology as the theoretical underpinning to research and method as techniques employed to collect and analyse data. This results in a disproportionate focus on method, irrespective of theory. Researchers have become over-reliant on conventional methods such as focus groups and interviews, motivated by assumptions about their acceptability, in spite of concerns that such methods limit depth of inquiry. ${ }^{12} 131415$

Healthcare researchers working with qualitative methodological paradigms seem to be in a double bind. Criticised from within the qualitative research community, they also have to contend with the dominance of scientific method in biomedical research. To gain ethical approval and to publish in scientific journals they must defend their research in terms of the transferability, dependability, credibility, and generalisability of their results. ${ }^{16}$ They use member checking, triangulation, insider/outsider articulation of concepts and formal/informal group analysis to do this. ${ }^{16}{ }^{17} 18$ Such techniques are supported by those who offer guidelines for the review of qualitative studies ${ }^{19} 20$ although this in turn provokes complaints of the use of "jargon and many strangely unscientific terms" "21 $^{2}$ and accusations of "sloppy work". ${ }^{22}$ Perhaps, however, because of this desire to meet supposed scientific expectations of objectivity, though validity is frequently raised as a concept, it is rarely discussed in terms of its relevance to methodology, research design or the relationship between methodology and the research aims and objectives. Looking for validity through group analysis and member checking-for example, may undermine researcher responsibility, ${ }^{10}$ while attempts to arrive at a consensus of opinion also divert attention from the individual's views. ${ }^{12}$ The scientist's desire to arrive at a "moment of truth" may overshadow the "journeying toward" possible multiple "truths".

It is within this rigidity of application and the desire to replicate scientific method, that we find the major differences between conventional methodologies and their less conventional counterparts. The metaphor of the edgelands reminds us, however, of the importance of work that does not conform to our preferred, neatly regulated landscape. Researchers at the edgelands of qualitative methodology argue for a relaxation of the rigid frameworks we have built around the presentation of results and the interpretation of findings to allow room for the unexpected to happen, fresh insights to be acquired, and theoretical perspectives to be developed.

This broadening of qualitative methodologies does not simply offer adjuncts to more traditional data collection approaches, or ploys to elicit data in different ways. Rather, it presents alternative epistemic positions from which to view the world, in which the research process is a process of discovery. Those working at the edgelands of qualitative methodology, a disparate group of researchers from a range of disciplines such as health services research, psychology, nursing, anthropology, and sociology all share in common the need to concentrate on that process of discovery while retaining a sense of the unknown. The researcher is often seen to be taking personal responsibility for research findings, irrespective of peer endorsement and without a mind to group analysis (either formal or informal). ${ }^{23}$ Arriving at a conclusive end point is secondary to the search for one and leaving nothing to chance is seen as counterproductive to creativity. As Nigel Rapport has commented:

For something to be true in human life, does it have to be observably replicated or replicatable (quantitative); and does a sample of events of the same kind have to be taken into account so that the representativeness of the new 
information can be ascertained? Alternatively, can one accept something is true if observed only by one person on one occasion (qualitative), both the manner of observation and the nature of the thing observed precluding replication? Indeed, can something be imagined to be true if it is unique, its own kind, and while implicated in other things is not them and not like them? ${ }^{5}$

Both the newer and more traditional qualitative methodologies fall into three strands that cover all the qualitative methodologies, finding recognition through their applicability to a variety of health and social care settings. The three strands: arts based methodology, narrative based methodology, and redefined methodology, are outlined below.

\section{ARTS BASED METHODOLOGY}

Arts based methodology emphasises the visual rather than the verbal, seeking to overcome logocentrism, and looking to a multisensory exploration of events and behaviours, offering visual and performative expression to meanings we ascribe to our lives. Arts-based methodology links back to Dilthey's ideas about the Geisteswissenschaften (the human sciences) as being distinct from the Naturwissenschaften (the natural or physical sciences). The subject matter of the human sciences is the human world, characterised by Geist: "mind, thoughts, consciousness, values, feelings, emotions, actions and purposes", finding objectification in "languages, beliefs, arts and institutions". ${ }^{18}$ Within arts based methodology, Geist is explored and expressed through visual presentations of unique and particular understanding. Such approaches attempt to visually recreate the research participant's world through a concentration on the sensory and the emotive. When people are allowed to create visual representations of their worlds-for example, photographs, paintings, sculpture, or through acting, they conjure up experience to be interpreted in different ways. Arts based research enables people to express experiences that may otherwise be overlooked. Children can paint or sculpt experiences they have had while they were ill that they may find difficult to articulate in other ways. Similarly the physically or mentally ill or patients with a speech impediment may turn to a variety of creative media to give meaning to experience. Arts based methodology encourages the creator-the photographer, painter, researcher, subject-to present their relationship to the world in a very particular way and this particularity may also be considered by the researcher alongside the visual stimuli offered. Arts based methodologies often rely on the use of displacement techniques, such as vignette technique. ${ }^{24}$ These are techniques employed to shift attention from the research participant onto an unknown other. ${ }^{24}$ As such, research participants are offered a choice regarding the degree to which they "enter" themselves into the unfolding research story. In this way, they can opt to remove themselves from direct association with the vignette being presented to offer an outsider perspective.

\section{Photo elicitation techniques on a hospital ward}

One example of arts based methodology's concomitant methods is photo elicitation technique, which has been used to explore patient experience of care on a hospital ward. ${ }^{25} 26$ Radley and Taylor, in their 2002 study of patient recovery from hospital, used photographs taken by patients in conjunction with written narratives and interviews to examine the relationship between the physical setting and recovery, with patients taking photographs of their hospital environment to be discussed in the context of later interviews. Photo elicitation used in this way has the ability to move qualitative inquiry beyond the verbal and textual to allow patients to represent their space through an image, encapsulating space, placement in the room, and relationships with objects. The photograph becomes a vehicle through which patients identify aspects of their stay and their settings that are particularly poignant or "salient". ${ }^{25}$ Photographs act as conduits to narratives that are "routed through the image" and stand as "triggers for memory". ${ }^{25}$ They encourage communication of "significant experience" and provide solid, visual evidence that can be called upon at a later date. Radley and Taylor ${ }^{25}$ remark that by offering patients the opportunity to control the editing process, photographs can reveal patients' innermost experiences of recuperation, with thoughts and feelings made visible, offering "direct entry into [a patient's] point of view" (Radley et al, ${ }^{25} \mathrm{p} \mathrm{79}$ ); adding a specific visual perspective on the world.

\section{NARRATIVE BASED METHODOLOGY}

Narrative based methodology considers how we live and the experiences we have, through the way we describe experience, the questions we pose to the world, and the solutions we offer. The process of questioning and finding answers can be expressed through our "stories of life" which give ongoing examples of experience and provisional solutions "that recapitulate actions already taken and are actions in themselves". ${ }^{27}$ Narrative based methodology pays much attention to social scientific knowledge based on stories as interpreted data and places these stores within a historical moment in order to define what the stories tell us and what importance they have for us. ${ }^{27}$ It is argued that as we attempt to make sense of the world through the stories we tell, we present a world that is "narratable"-given form and coherence. ${ }^{27}$ For the listener, the telling encourages the recording and interpretation of the storyteller's narration, which in itself is a representation of experience predefined by the storyteller.

\section{The patient story in narrative based methodology}

To explore people's experiences of illness in narrative based methodologies, stories are broken down into a number of aspects the contextual (aspects surrounding the event); the mantic (the emotive aspect); the semantic (the events as portrayed by the storyteller); the linguistic (the ordering of words and sentences and the use of emphasis); the historical (temporal or spatial); the cultural (according to ethnic or social groupings), and the biographical (life stories). Breaking down the story in this way, to consider any number of the above aspects, encourages researchers to consider linked or individual elements of the story and enables researchers not only to make sense of the story being told, but also to examine the presentation style, environment, and culture of the narrator. ${ }^{28}$ In contemporary contexts, qualitative methodology is moving forward by considering how narratives are used where communication between clinicians and patients is important, ${ }^{29}$ or where social anxiety or cultural mores need more in depth examination. The manner in which narratives can tell us about the contemporary illness story and negotiations that take place within the consultation is where discourse analysis really comes into its own. Here personal narratives are explored in minute detail for what they tell us about life experiences, biographical accounts of illness or illness events. Discourse analysis, by considering both question and answer formats, takes heed of all roles within the consultation and the manner in which informal talk within the consultation often turns into lengthy conversation. In the case of the recounting of illness events, the telling promotes a reordering of experience, ${ }^{27}$ such as the medical examination, to produce a calmer experience than that initially recorded. The original illness experience has been described as one of "personal chaos", or "disembodiment" ${ }^{\prime 30}{ }^{31}$ the reordering of which, as in the case 
of the disruption of chronic illness, enables patients to reconstruct a coherent self through narrative. ${ }^{30}$

\section{Discourse analysis techniques in the interior of consultations}

By recording examples of interaction between individuals, transcribing them in detail, and then interpreting the text, we are able to get closer to meaning as presented by the research participant or patient, to reflect on the context in which meaning is given, and to consider the rhetorical organisation of events. Take for instance an example of discourse analysis in a modern context-the patient consultation within the general practitioner's (GP's) surgery. ${ }^{32}$ The elderly woman in the consultation has returned to the GP to receive test results for cholesterol. From the outset, she is told that "we" (that is, she and the doctor), must try and decide on a course of action, and she is implicitly involved in the decision making process. The doctor gives her two options: either to "leave things as they are", (to diet- "being careful about what you eat") or else to "go for treatment with some tablets".

Analysis of a scenario such as this can illustrate how the more traditional techniques of conversation analysis have moved forward. Not only can the analysis process reveal all aspects of narrative examination (context, mantic, semantic, linguistic, historical, cultural, and biographical), rather than-as with conversation analysis-concentrating on one or two aspects, it can also use the process itself to indicate the important of communicative revelations in terms of the meaning patients give to their problems, thus taking us toward greater clarity regarding communication/miscommunication between patient and professional. Line 64, in the example below indicates a fundamental difference of understanding (mantic and semantic aspects) between the patient and the doctor. She wants to "get rid of it" (the cholesterol). She thinks it is the problem, the illness, the focus of her feeling unwell. The doctor is attempting to explain that it is a risk factor, that it is a natural constituent of our physiology, but when at high concentration, contributes to possible heart disease in the future (contextual aspects). Both parties continue along these communication lines and it becomes clear that while the patient understands that she has to rid herself of "it", the doctor fails to grasp her perspective and perseveres in an attempt to involve her in a choice of how to lessen the risk posed by the cholesterol. By concentrating on breaking down stories according to a variety of different aspects, looking at the process of discovery and by paying attention to the "participant position", discourse analysis is currently achieving both an in depth exploration of the "stories of life" and a critique of "the act of telling" as one ongoing, fluid process.

\section{REDEFINED METHODOLOGY}

Though not new, redefined methodologies are those that contain a strong element of personal reflexivity. They

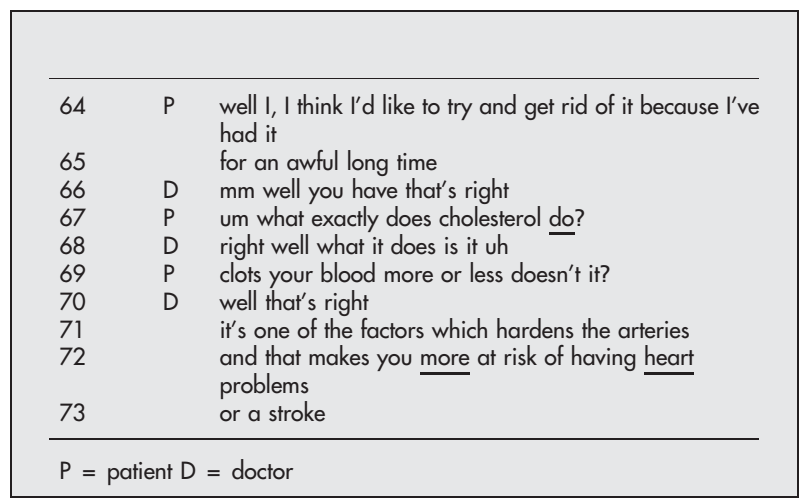

are methodologies that use the concepts of "embodied understanding", ${ }^{33}$ "self reflection", 5 "self esteem", "cognitato" (cognition, self grasping) ${ }^{34} 35$ as the basis for approaching the meanings we bestow upon the world. Redefined methodologies are introspective and critically self examining in their reflexive nature, leading to a redefinition of the parameters upon which they are based. The features of these methodologies are continually changing through ongoing experimentation, reflexivity, and theoretical development, in contrast to the more traditional view that methodologies and methods, once developed, should be followed like recipes, without deviation from the established procedures. These methodologies are never constant. According to Todres and Wheeler, progressive methodologies are always "on the way", ${ }^{36}$ because research context, participant, and researcher are always changing and adapting. In conventional approaches to sampling and data collection much attention is paid to the careful selection of participants and to stability in the research population. In experimental designs the desire is to control the sample, and loss to follow up is a major concern; similar concerns may be found even in some qualitative studies. Researchers working in redefined methodologies, by contrast, may modify the research in response to changes in participant groupings as a study develops. Participants may opt in or out of the study, and this in turn may affect data collection schedules, methods used or the general conduct of the research.

\section{Reflexivity within redefined methodology}

Reflexivity permeates interpretive anthropology, hermeneutic method, and descriptive phenomenological method, aided by an appreciation of the connecting conversations within patients' stories and the way in which stories unfold through a number of anchor points. The reflexive approach leads researchers into a relationship with participants, enabling them to elicit a complex appreciation of experience. The approach dismisses step by step method development in favour of appropriate responses to research questions, unrestricted by dogma and predefined structure. Structure itself is self imposed and it is the researcher's responsibility to respond to the unfolding study. Interpretive anthropologyfor example, when used within a healthcare setting, has the aspiration of being in constant flux, ${ }^{37}$ calling into question disciplinary knowledge and conventional and disciplinary divisions. ${ }^{5}$ It is dynamic in its development, through its recognition of the reflexive nature of the human condition-the way our consciousness of ourselves and our worlds is in constant dialectical interplay with the nature of self and world. ${ }^{5}$ This approach favours openness to human imagination or imaginative knowing, acknowledging that something imagined is also a truth and being ready to accept the pathways down which our imagination takes us is its primary tool.

\section{Interpretive anthropological techniques in the "portering" experience}

Rapport adopted an interpretive anthropological approach to study national identity in a Scottish hospital, working as a porter through a year's participant observation. The research illuminates not only different modes of communication within a hospital setting but also how different professional groups approach patient interaction and information giving. Rapport's work shows "the complex of porters' relations and attitudes to doctors in the hospital" and summarises "the porter's point of view: an experience of hospital hierarchy, and its obviation". ${ }^{5}$ In this study Rapport highlights a reflexive position whereby porters transcend institutional differentiation, "to arrive at relations deriving from an existential or at least wider, social awareness, and giving onto a generically human community". ${ }^{5}$ Obviation of hierarchy, by undermining and overcoming stereotypes, 
having a sense of "otherness" and "nothingness", and rising above the strictures of overwhelming authority, enables porters to manage uncomfortable daily situations of humiliation and division. Redefined methodology in this study enabled Rapport to embrace personal experience, self reflection, and in depth, extensive observation to make sense of porters' routines, relations, and behaviours. This affected both the manner in which data were collected, understood and discussed, and the way in which "self" is clearly present in experience and reflection. Redefined methodology freed "Rapport the anthropologist" to become "Rapport the porter"; offered imaginative vision, and enabled the researcher to consider the ambiguous nature of situations observed to reveal the rich "lifeworld" of the porter.

\section{DISCUSSION}

The basic premise of quantitative biomedical research is that things are true because they occur in large numbers of people, alike in some relevant respect but randomly chosen. A key characteristic of science is that scientific knowledge is independent of time and place or, if there are variations, these can be explained within the terms of the relevant theory. Barometric pressure varies with altitude in the same way, regardless of whether the measurements are taken in the Northern or Southern hemisphere. Scientific knowledge is thus said to be value free: it does not matter what my preferred barometric pressure might be. These assumptions give science its explanatory and predictive powers. We have argued in this paper, however, that there are other kinds of truths and other ways of journeying toward and knowing them, and that these truths and these ways of knowing are as important and as useful as those of traditional science.

For biomedicine, truths about biological function are impersonal, investigated by impersonal methods. For the patient, however, the experience of biological functioning is unique and highly personal. For biomedicine, no matter how often you repeat the experiment or conduct the investigation under the same relevant conditions, the result is expected to be the same. In matters of the human experience of life, however, not only can you not step in the same river twice, arguably, as Tom Wolfe suggests, you cannot step in the same river once. If only one person has, or imagines an experience, as Nigel Rapport says, this is nevertheless a truth for that person. The humane practice of medicine, if it is to help people in their experience of illness, must acknowledge this uniqueness of the individual as subject and try to respond, rather than refusing to engage with any claims that cannot be supported by findings from a probabilistic sample.

However, for people to speak of their unique personal experiences is difficult and may be distressing. Keeping our experiences, thoughts, and emotions private is a necessary element of our selfhood and unwanted disclosure to people with whom we lack the necessary intimacy is a threat at the very least to our comfort. Leaving aside self inflicted damage such as alcoholic cirrhosis, the quantifiable variations in the function of our liver are perhaps less central to our concept of self than are our personal responses to our experience of liver disease. The disclosure of an abnormal liver function test does not reveal our character, the kind of persons we really are, in the same way as an admission of fear about the nature of our illness and its prognosis. As Sartre ${ }^{38}$ has argued, if we are caught in an embarrassing situation we feel shame because we have allowed others to see the kind of person we really are. To have liver cancer is not shameful, whereas we may be ashamed of being seen to be a coward.

Jensen $^{39}$ has argued that medicine has become a practice without subjects: the persons of both doctor and patient have disappeared from modern medicine. Doctors have become embodiments of truths about the nature of disease, incarnations of scientific evidence. Qualitative methods of the kind we have described in this article allow people to express their point of view about the experience of illness and treatment. Truths about our experiences, our fears, and our points of view, are explicitly outside the scope of science, which is committed to an investigation of that which is observable and independently verifiable. Concerns that cannot be accessed by means of the experimental technique can be accessed, for example, using arts based, narrative based or redefined methodologies, not by looking for the statistical norm for a population but by exploring the unique particularity of an experience for one person. Differences between individuals are as important as similarities in the provision of healing and care. We need to know how people understand their situations, not just how we fix the pathology. The science of diagnostics and therapeutics rests on assumptions about what is desirable and normal, but these assumptions do not hold true for everybody. It is well documented that not all deaf or blind people want their hearing or sight restored, and not all paraplegics wish to resume the upright position. Some deaf couples wish for deaf children. A patient with stomach cancer may prefer a narrative in which six months of supportive complementary therapy with good quality of life will probably be followed by death, to the probability of death after six months of aggressive chemotherapy. Openness to alternative ways of being and to different, individual truths about wellbeing are critical to humane health care but beyond the grasp of biomedicine and scientific methods.

If we are to understand the individual's experience and restore both patient and practitioner as subjects in health care we need methodologies that can provide insights in ways that are illuminating and also ethically acceptable. We cannot know how best to provide support and foster wellbeing unless we have ways of understanding what counts as supportive and how people experience wellbeing. Giving blood samples for laboratory analysis may be less distressing than giving information about the kind of person we really are. So there is an ethical imperative for us to investigate these questions in ways that are effective but that incur as little risk as possible. Vignette technique-for example, allows us to avoid the direct questioning of people about their personal experiences or views. Vignette technique poses hypothetical situations, asking people to imagine that they were in such a situation and to say how they or others might react. Narratives do not only record the past, they also envisage the future, and by presenting participants with alternative narratives and inviting them to choose which narrative they would prefer to be a part of, we can enable them to offer insights into alternative, imagined realities. An imagined truth is none the less a truth.

Research of this kind holds dangers for all concerned. In a climate where practice is driven so absolutely by the randomised controlled trial and the systematic review, asking clinicians to take seriously the results of autoethnographies or photo elicitation projects is difficult. Prestigious academic journals may be reluctant to publish work not based on randomised samples, however inappropriate randomisation may be given the context. Policy makers, planners, and funding bodies may be reluctant to allow the development of services or treatment approaches based on the personal preferences of patients rather than on the data from phase two and phase three trials. Such services, if allowed to develop, may look untidy. They may not fit conveniently into categories such as primary, secondary or tertiary care and may lack objective outcome measures. However, many of the things we most appreciate and value in life do not fit neatly into categories and lack objective outcome measures. Thus for the time being at least such work goes on in the metaphorical 
edgelands, where there are risks, and the normal rules of conduct cannot entirely be relied upon, but those who attend to what happens in such places or have the good fortune to be touched by the results may find their lives enriched as a result.

\section{Authors' affiliations}

F Rapport, G Elwyn, Primary Care Group, Swansea Clinical School, Centre for Health Improvement and Evaluation (CHIRAL), University of Wales Swansea, Singleton Park, Swansea, UK

P Wainwright, Faculty of Health and Social Care Sciences, Kingston University and St Georges Medical School, Sir Frank Lampl Building, Kingston Hill, Kingston upon Thames, Surrey,UK

\section{REFERENCES}

1 Shoard M. Edgelands. In: Jenkins J, ed. Remaking the landscape: the changing face of Britain. London: Profile, 2000.

2 Rapport F, Wainwright P, Elwyn $G$. The view from the edgelands [editorial]. Med Humanit 2004:30:5-6.

3 Moran J. Interdisciplinarity: the new critical idiom. London: Routledge, 2002

4 Fay B. Contemporary philosophy of social science. Oxford: Blackwell, 1996.

5 Rapport N. From the porter's point of view. In: Rapport F, ed. new qualitative methodologies in health and social care research. London: Routledge, 2004

6 Allmark P. Nursing philosophy 4. Popper and nursing theory 2003;4:4-16.

7 Rapport F. Shifting sands in qualitative methodology. New qualitative methodologies in health and social care research. London: Routledge, 2004

8 Giorgi A. The status of Husserlian phenomenology in caring research. Scand J Caring Sci 2000;14:3-10.

9 Giorgi A. Concerning the application of phenomenology to caring research. Scand J Caring Sci 2000;14:11-15.

10 Maggs-Rapport F. Best research practice: in pursuit of methodological rigour. J Adv Nurs 2001;35:373-83.

11 Paley J. Husserl, phenomenology and nursing. J Adv Nurs 1997;26:187-93.

12 Biley FC. An experiment in accessing pandimensionality: the literary poetics and deconstruction techniques of William S Burroughs applied to the science of unitary human beings. Seventh Rogerian Conference, Nursing and the Changing Person Environment. New York, USA, 1988.

13 Hockey J. Interviews as ethnography? Disembodied social interaction in Britain. In: Rapport N, ed. British subjects: an anthropological Britain Oxford, Berg, 2002.

14 Jones K. Beyond the text: an Artaudian take on the non-verbal clues revealed within the biographical narrative process. International Sociological Association International Conference. Kassel, Germany, 2001.

15 Jones K. The turn to a narrative knowing of persons: one method explored. Nursing Times Research 2003;8:60-71.
16 Lincoln YS, Guba EG. Naturalistic inquiry. London: Sage, 1985

17 Denzin NK. The research group. A theoretical introduction to sociological methods. New York: McGraw Hill, 1978.

18 Van Manen M. Researching lived experience: human science for an action sensitive pedagogy. London, Ontario: Althouse Press, 1990.

19 Mays N, Pope C. Rigour and qualitative research. BMJ 1995;311:109-12.

20 Mays N, Pope C. Assessing quality in qualitative research. BMJ 2000;320:50-2.

21 Isbister W. Good communication is essential part of educational process [letter]. BMJ 2000;320:1729.

22 Poses R, Levitt N. Antirealism is an excuse for sloppy work [letter]. BMJ 2000;320:1729.

23 Giorgi A. Description versus interpretation: competing alternative strategies for qualitative research. Journal of Phenomenological Psychology 1992;23:119-35.

24 Finch J. Research note, the vignette technique in survey research. Sociology 1987;21:105-14.

25 Radley A, Taylor D. Images of recovery: a photo-elicitation study on the hospital ward. Qual Health Res 2002;13:77-99.

26 Radley A, Taylor D. Remembering one's stay in hospital: a study in photography, recovery and forgetting. London: Sage, 2003.

27 Frank AW. The Politics of Authenticity: International Conference of Advanced Research Methods. Alberta, Canada, 2001.

28 Greenhalgh T, Hurwitz B. Narrative based medicine. London: British Medical Journal Books, 1998.

29 Launer J. Narrative based medicine: a new paradigm for primary care. Cardiff: Health Communication Workshop, Cardiff Communication Research Centre, 2002.

30 Riessman CK. Narrative analysis. Newbury Park, CA: Sage, 1993.

31 Riessman CK. Strategic uses of narrative in the presentation of self and illness: a research note. Soc Sci Med 1990;30:1195-1200.

32 Gwyn R, Elwyn G, Edwards A, et al. The problematic of decision sharing: deconstructing "cholesterol" in a clinical encounter. Health Expect 2003;6:242-54.

33 Todres L. The meaning of understanding and the open body: some implications for qualitative research. Existential Analysis 2004;15:38-54.

34 Chadderton H. Hermeneutics and nursing research. In: Rapport F, ed. New qualitative methodologies in health and social care research. London: Routledge, 2004

35 Husserl E. The idea of phenomenology. The Hague: Nijhoff, 1964

36 Todres L, Wheeler S. The complementarity of phenomenology, hermeneutics and existentialism as a philosophical perspective for nursing research. Int J Nurs Stud 2001;38:1-8.

37 Rapport N, Overing J. Social and cultural anthropology: the key concepts. London and New York: Routledge, 2000.

38 Sartre JP. Being and nothingness: a phenomenological essay on ontology. New York: Washington Square, 1992.

39 Jensen J. Ethics in practice [paper]. Communication, Ethics and Medicine Conference. University of Linkoping, Sweden, 4 Jun, 2004. 